\title{
Notes on the vocalizations of Wattled Honeyeater (Foulehaio carunculatus)
}

Peter Boesman

In the following we briefly analyze and compare voice of the three races of Wattled Honeyeater (Foulehaio carunculatus). We also try to quantify the extent of any vocal differences using the criteria proposed by Tobias et al. (2010), as a support for taxonomic review. We have made use of sound recordings available on-line from Xeno Canto (XC) and Macaulay Library (ML).

Main vocalizations of all three races are similar and varied, either short phrases of a few melodious or gurgling whistles repeated several times, or somewhat longer series of different melodious whistles. Some examples:

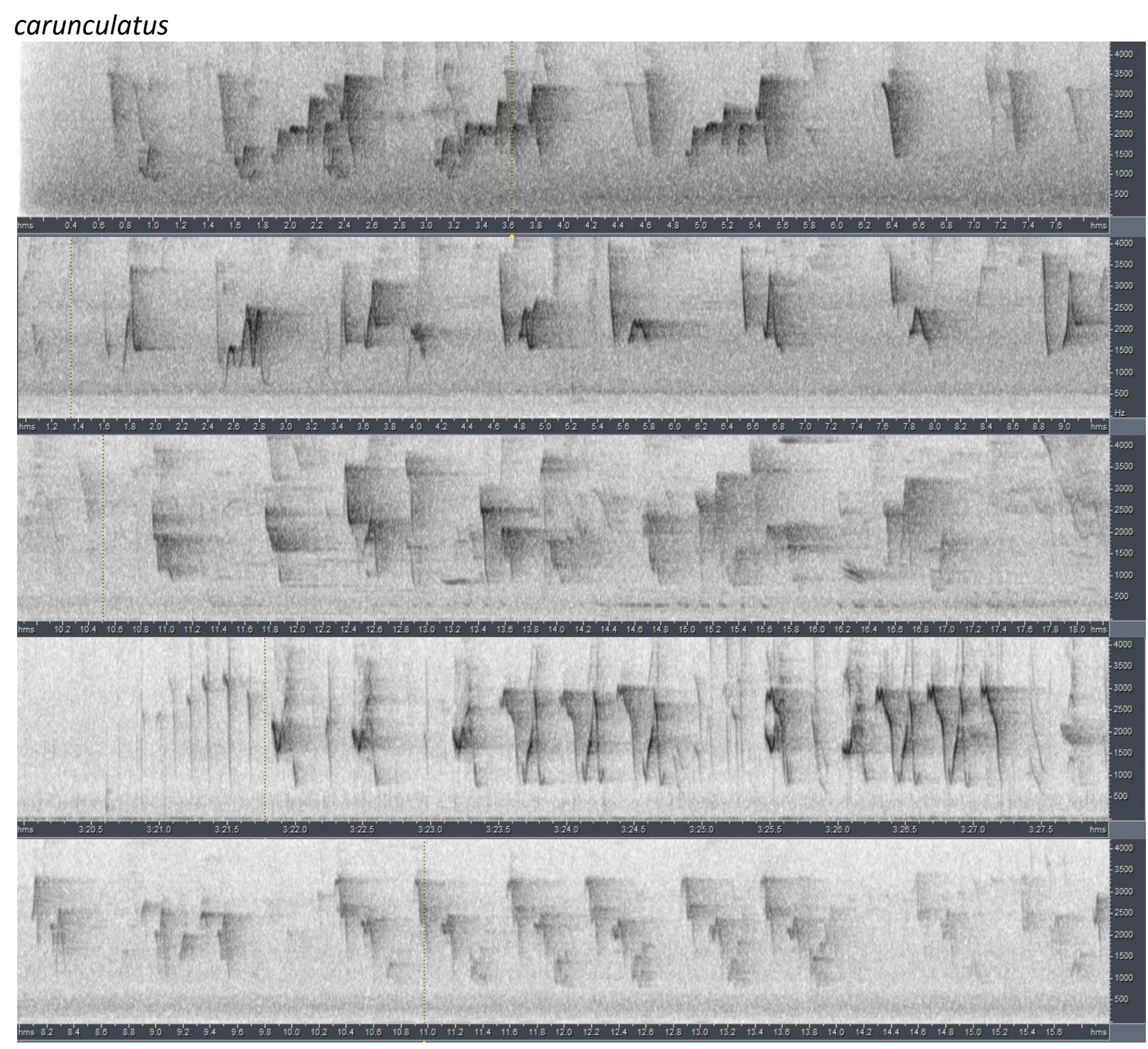


HANDBOOK OF THE

BIRDSPF TUE WORLD

ORNITHOLOGICAL NOTES

procerior

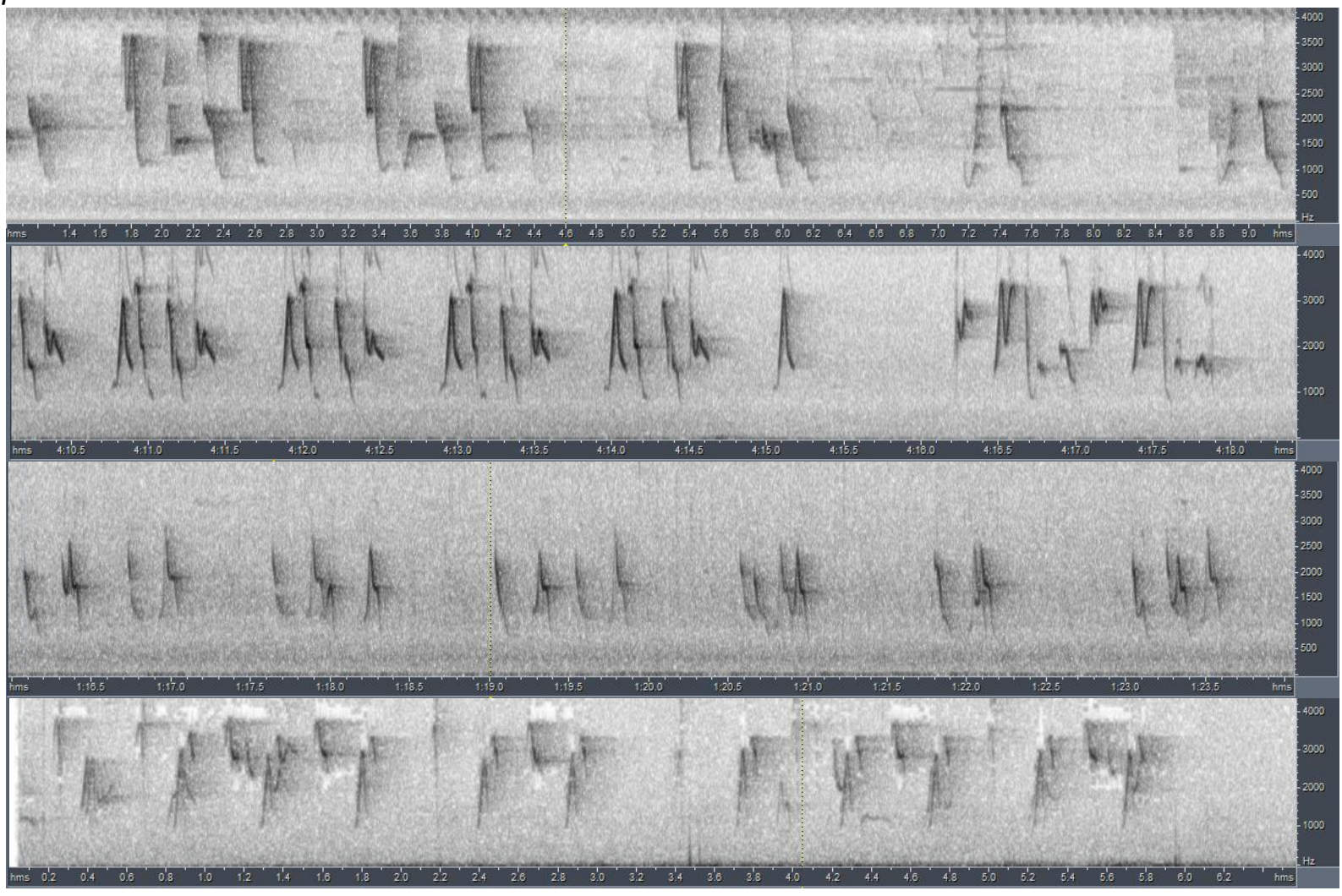

taviunensis

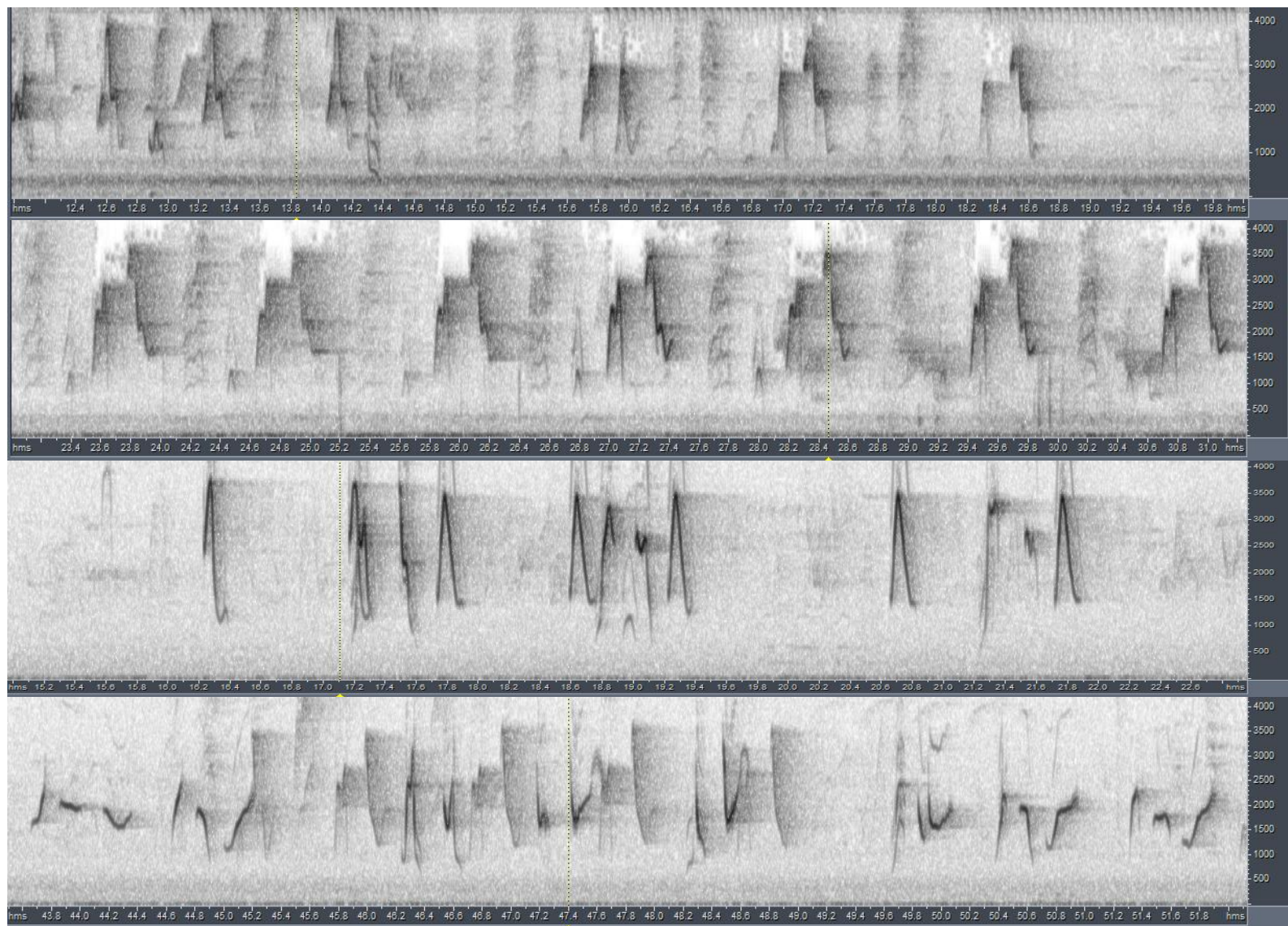



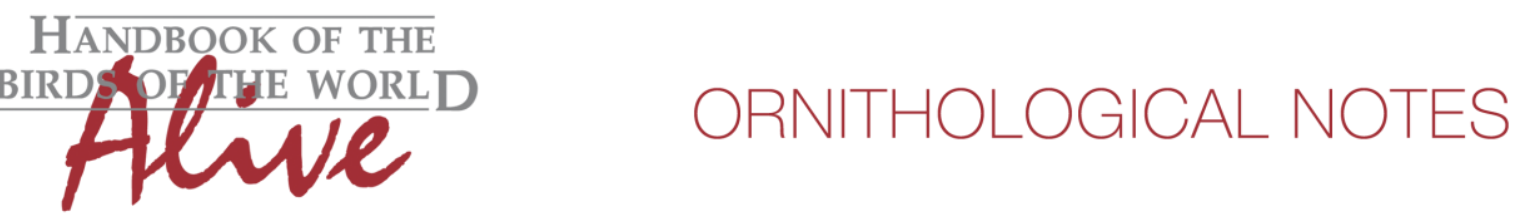

As can be seen from the above examples, basic sound parameters such as frequency range, max. freq., note length, pace etc. are all very much the same. Even note shapes are quite similar.

Given the extent of variation, one would have to analyze a very extensive series of recordings to prove any diagnosable difference, e.g. the existence of certain whistles unique to a single race, or the frequency of delivery of certain phrases, but resultant scores following Tobias criteria can be expected to be very small at most.

(e.g. from the available recordings, it would seem that only taviunensis uses occasionally short upslurred notes-> allow score 1)

Based on this brief analysis however, we haven't found any clear vocal differences.

This note was finalized on 25th November 2015, using sound recordings available on-line at that moment. We would like to thank in particular the many sound recordists who placed their recordings for this species on XC and ML.

\section{References}

Tobias, J.A., Seddon, N., Spottiswoode, C.N., Pilgrim, J.D., Fishpool, L.D.C. \& Collar, N.J. (2010). Quantitative criteria for species delimitation. Ibis 152(4): 724-746.

\section{Recommended citation}

Boesman, P. (2016). Notes on the vocalizations of Wattled Honeyeater (Foulehaio carunculatus). HBW Alive Ornithological Note 151. In: Handbook of the Birds of the World Alive. Lynx Edicions, Barcelona. (retrieved from http://www.hbw.com/node/932081 on 17 August 2016). 